\title{
The effect of dietary energy and protein level on the production of growing ostriches
}

\author{
T.S. Brand ${ }^{1}$, C.J. Nell ${ }^{2}$ and S.J. van Schalkwyk ${ }^{2}$ \\ ${ }^{1}$ Elsenburg Agricultural Centre, P Bag X1, Elsenburg, $7607,{ }^{2}$ Oudtshoorn Experimental Farm, PO Box 351, Oudtshoorn, 6620
}

\section{Introduction}

The Ostrich Industry reached a very low level during 1997/1998. Since feeding costs contribute approximately $70-80 \%$ of the total cost of ostrich production, several studies were conducted at that stage in an attempt to decrease the production costs of intensive ostrich enterprises. Swart (1988) found that the ostrich are able to utilize fibre components such as hemicelloluse and cellulose. In spite of these findings, ostriches were still mostly fed on high concentrate diets. In a study by Salih et al. (1998) it was concluded that ostriches performed well on diets with high levels of roughage and a definite economic advantage was detected. In that study lucerne hay (which is well known for its good quality) was use as source of fibre. This study was conducted to evaluate low quality roughage as source of fibre in diets of growing ostriches. The effect of protein level on the production performance of ostriches was evaluated simultaneously.

\section{Material and Methods}

Eighteen groups of ostriches with 5 birds per group were used as experimental units. Birds were fed from approximately 4 to 11 months of age (25-90 kg) and slaughtered. Diets were fed according to a 3 (energy level) x 3 (protein level) factorial design. Energy levels of 9.0, 10.5 and 12.0 MJ ME and protein levels of 13, 15 and $17 \%$ were used. Amino acid levels were adapted according to protein levels. Oat bran was use as source of fibre and replaced maize as energy source in the diets. Soybean oilcake was used as a source of protein.

\section{Results and Discussion}

The effect of dietary energy level on the production performance of growing ostriches is presented in Table 1. No significant interactions occurred and the main effects are presented separately. Protein levels (as well as amino acid levels) as used in this study had no effect on the growth performance of the ostriches from $25-90 \mathrm{~kg}$. The energy/fibre level had no effect on the growth rate of the birds. Birds fed the low energy (high fibre) diets, however, consumed significantly more feed, which also resulted in a lower feed conversion ratio for this group. Skin surface area was significantly affected by the energy content of the diet, with a smaller skin surface area on birds fed the 9.0 MJ ME diet. Protein content did not affect skin surface area. The energy content of the diets did not affect the quality of the skins (quality was determined by grading, which was mainly determined by the number of scratches on the skin). A significant effect of protein content on the quality on the skin was however found, with more skin damage due to scratches on the high protein diet. Although difficult to explain, there is a possibility that a high protein content in the diet may lead to restlessness in these birds. This may be due either to an accumulation of ammonia or glutamate in the brains of these animals, caused by a excessive intake of protein.

Table 1 The effect of level of energy and protein on the performance of ostriches from 4 to 11 months of age (25 $89 \mathrm{~kg}$ )

\begin{tabular}{llllc}
\hline \multicolumn{1}{c}{ Measurement } & \multicolumn{3}{c}{ Level of Energy (MJ/kg ME) } & Standard Error \\
& 9 & 10.5 & 12 & \\
\hline Dry matter intake, kg/bird/day & $2.90^{\mathrm{a}}$ & $2.63^{\mathrm{b}}$ & $2.41^{\mathrm{b}}$ & 0.06 \\
Growth rate, g/bird/day & $285^{\mathrm{NS}}$ & $309^{\mathrm{NS}}$ & $313^{\mathrm{NS}}$ & 11.00 \\
Feed conversion, kg/feed/kg weight gain & $6.79^{\mathrm{a}}$ & $7.45^{\mathrm{ab}}$ & $8.81^{\mathrm{b}}$ & 0.39 \\
Skin surface area dm ${ }^{2}$ & $134^{\mathrm{a}}$ & $137^{\mathrm{ab}}$ & $138^{\mathrm{b}}$ & 1.2 \\
Grade 1, skins ${ }^{+} \%$ & 41 & 46 & 46 & 5.9 \\
\hline & \multicolumn{4}{c}{ Level of Protein $(\%)$} \\
\hline Dry matter intake, kg/bird/day & 13 & 15 & 17 \\
Growth rate, g/bird/day & $2.32^{\mathrm{NS}}$ & $2.14^{\mathrm{NS}}$ & $2.21^{\mathrm{NS}}$ & 0.07 \\
Feed conversion, $\mathrm{kg} /$ feed/kg weight gain & $300^{\mathrm{NS}}$ & $299^{\mathrm{NS}}$ & $308^{\mathrm{NS}}$ & 11.00 \\
Skin surface area, dm & $8.13^{\mathrm{NS}}$ & $7.49^{\mathrm{NS}}$ & $7.52^{\mathrm{NS}}$ & 0.39 \\
Grade 1, skins, \% & 135 & 136 & 138 & 1.2 \\
\hline
\end{tabular}

${ }^{\sqrt{S}}$ Not significant; ${ }^{\mathrm{a}, \mathrm{b}}$ Denote significant $(\mathrm{P} \leq 0.05)$ differences in rows; ${ }^{+}$Indicates less skin damage due to scratches 


\section{Conclusions}

This study contributes to the present limited guidelines for ostrich nutrition. It was indicated that low quality roughage might be used at high levels in ostrich nutrition, although performance will be decreased accordingly. Protein levels as low as $13 \%$, on the other hand, did not effect performance, while a high protein intake may lead to lower quality skins. The latter hypothesis should be subject to further testing.

\section{Acknowledgements}

The Klein Karoo Cooperation, Oudtshoorn, supported this study financially.

\section{References}

Salih, M.E. et al., 1998. Proc 2nd Int Ratite Conf. South Africa. pp 31 - 37.

Swart, D., 1988. PhD Tthesis, University of Stellenbosch. 